\title{
Plasma C4 level was associated with mortality, cardiovascular and cerebrovascular complications in hemodialysis patients
}

\author{
Yuqing Chen ( $\nabla$ cyq@bjmu.edu.cn ) \\ Peking University First Hospital \\ Zheyu Xing \\ Peking University First Hospital \\ Yaqin Wang \\ Peking University First Hospital \\ Kunjing Gong \\ Peking University First Hospital
}

\section{Research Article}

Keywords: hemodialysis, complement factor 4, complement activation, cardiovascular and cerebrovascular diseases, prognosis, all-cause mortality

Posted Date: February 24th, 2022

DOl: https://doi.org/10.21203/rs.3.rs-1342104/v1

License: (c) (i) This work is licensed under a Creative Commons Attribution 4.0 International License. Read Full License 


\section{Abstract}

Background: Patients on maintenance hemodialysis (HD) exhibit a high risk of death, cardiovascular and cerebrovascular diseases (CCDs). Previous studies indicated complement activation associated with the increased risk of cardiovascular diseases in HD patients. This study aimed to explore whether the critical complement factors associated with the adverse outcomes in HD patients.

Methods: A total of $108 \mathrm{HD}$ patients were included and followed up for 52 months. The baseline clinical characteristics and plasma C3c, $\mathrm{C} 1 \mathrm{q}, \mathrm{CFH}$, CFB, C4, MAC, C5a, C3a and MBL were measured. The three endpoints were death, cardiovascular and cerebrovascular events (CCEs) and the composition of them. Univariate and multivariate Cox regression identified factors associated with the three endpoints respectively. $\mathrm{X}$-tile analyses determined the optimal cut-off values for high risks. Restricted cubic spline plots illustrated the dose-response relationships. Correlations between the complement factors and risk factors for CCDs were analyzed.

Results: Baseline plasma C4 was finally selected by univariate and multivariate Cox regression analyses for three endpoints, including all-cause mortality, CCEs and the composition of them. When baseline plasma C4 exceeded $0.47(P=0.001)$ or $0.44(P=0.018) \mathrm{g} / \mathrm{L}$ respectively, the risks for death or achieving the composite endpoint enhanced significantly. The relationships of C4 and HR for the three endpoints showed a positive linear trend. Plasma C4 had prominent correlations with blood TG $(r=0.62, P<0.001)$ and HDL $(r=-0.38, P<0.001)$.

Conclusions: A higher baseline plasma C4 level was significantly associated with the future incidence of decease, CCEs and either of them. Plasma C4 level correlated with blood TG and HDL.

\section{Introduction}

Hemodialysis (HD) has dominated the renal replacement therapy for decades among more than 2,000,000 patients afflicted with end-stage renal disease (ESRD) (1,2). Despite tremendous progress in HD techniques, the mortality and morbidity of complications (cardiovascular, cerebrovascular and infection diseases especially) remain extremely high(3). Chronic kidney disease (CKD) is proved as an independent risk factor for all-cause mortality as well as cardiovascular and cerebrovascular diseases (CCDs) $(4,5)$. Although maintenance HD contributes to extend the patients' life against kidney failure, it also poses vascular injury on the already compromised cardio-cerebrovascular system $(6,7)$.

Recent decades have witnessed a series of studies about risk factors for mortality and complications in HD patients (8). Apart from traditional risk factors (such as aging, comorbidities, obesity and dyslipidemia), more emerging risk factors (such as oxidative stress, endothelial dysfunction and chronic inflammation) (9) are identified to be substantially significant. Since the first report about the influence of HD on complement system (10), complement activation during HD was thoroughly investigated (11-14). Previously, our cross-sectional study also observed complement activation among $108 \mathrm{HD}$ patients, representing a decreased level of plasma C3c and complement factor B (CFB), and an elevated level of plasma mannose-binding lectin (MBL), C3a and C5a, compared with normal controls (15). Further, diverse complement proteins, including MBL (16-18), C3 (19), C1q-adiponectin (2), membrane attack complex (MAC) (19), complement factor H (CFH) (20) and complement receptor 1 (CR1) (21) were confirmed as significant predictors for the incidence of cardiovascular events or death for HD patients. Besides, a body of large studies targeting normal population also revealed plasma C3, C4 $(22)$ and $\operatorname{MBL}(23,24)$ level were risk factors for cardiovascular diseases.

In the present study, we took advantage of a prospective cohort to identify the pivotal components of complement system associated with the outcomes of HD patients. Other risk factors were also taken into consideration to control confounding variables. Determination of the optimal cutoff points for the identified factors is of considerable reference value for the prediction of the adverse events.

\section{Materials And Methods}

\subsection{Patients}

A prospective study of 52 months (from October 2016 to February 2021) was conducted in a cohort of 108 patients on maintenance HD, recruited from a single center of Peking University First Hospital. The protocol has been described previously (15). In brief, all patients were on a three times weekly dialysis schedule and spKt/V > = 1.2. Patients with a significant inflammatory illness were excluded, defined as hypersensitive C-reactive protein (hs-CRP) $>50 \mathrm{mg} / \mathrm{L}$.

\subsection{Data Collection and Follow-Up}

The severity of baseline comorbidities was assessed by the modified Charlson comorbidity index (mCCI), which was reported as a strong predictor for mortality in $\mathrm{HD}$ patients (25). The $\mathrm{mCCl}$ is based on 19 certain comorbidities and excludes the subject's age (Table S1) and can serve as a prediction tool for 10-year survival $(25,26)$. 
During the study period, data on death and cardiovascular or cerebrovascular events (CCEs), considered as two endpoints respectively, were collected prospectively according to the medical records. Cardiovascular events were defined as the occurrence of ischemic heart disease [unstable angina pectoris, myocardial infarction, coronary artery bypass grafting (CABG) and/ or percutaneous coronary intervention (PCI)], sudden cardiac death and congestive heart failure(17). Cerebrovascular events were defined as stroke, ischemic insult, or newly diagnosed $>70 \%$ stenosis of the extracranial carotid artery(17). The composite endpoint, "decease or CCEs", was also assessed. Besides, censoring events were considered as renal transplantation, transfers to other HD centers or achieving the end of the study, and the date was recorded as the final followup date.

\subsection{Clinical and laboratory measurements}

Baseline clinical characteristics of the cohort have been published previously, as well as other laboratory measurements (15). In summary, baseline demographic information was acquired from medical records, and baseline blood samples were obtained before the start of a regular 4-h $\mathrm{HD}$ session for regular laboratory tests and the quantification of complement components. Plasma C3a, C5a, MBL and MAC (sC5b-9) levels were detected by commercial ELISA kits from Quidel Corporation (San Diego, CA) (15). We applied immunity transmission turbidity kits (Shanghai Beijia Biochemistry Reagents Co., Ltd) to quantify plasma C3c, CFB, CFH, C1q and C4 levels (15).

\subsection{Statistical analyses}

Statistical evaluation was conducted with SPSS 25.0 (SPSS Inc., Chicago, IL, USA) and GraphPad Prism v.8 (La Jolla, CA, USA). Continuous parameters were presented as mean \pm standard deviation or median (interquartile range), while categorical variables as proportions. In betweengroup comparisons were done using chi-squared tests, $t$ test or Mann Whitney $U$ test. Survival analyses were performed by using the univariate and multivariate Cox regression for three endpoints respectively. X-tile 3.6.1 software (Yale University, New Haven, CT, USA) (27) was exploited to determine the optimal cut-off value for plasma C4 level in our HD cohort. R 4.1.0 (The R Foundation, Vienna, Austria) was applied to visualize restricted cubic spline models (with 4 knots by RMS package) and correlation map (with Spearman's correlation coefficients by corrplot package). $\mathrm{P}<0.05$ was considered statistically significant. All confidence intervals (Cls) were stated at a 95\% confidence level.

\section{Results}

\subsection{Patient characteristics and outcomes}

A total of 108 patients with maintenance HD were enrolled according to the inclusion and exclusion criteria. The characteristics of the patient population have been reported previously (15). In brief, there were 62 males and 46 females aged $56 \pm 12$, undergoing HD therapy for 60 $(29,122)$ months at baseline. Other general characteristics probably correlated with prognosis and plasma complement factors (C3c, C1q, CFH, CFB, C4, MAC, C5a, C3a and MBL) are shown in table 1, stratified by death or alive.

Table 1

Baseline characteristics of the HD cohort stratified by outcome. 


\begin{tabular}{l|l|l|l}
\hline All patients & Died & Alive $^{\mathrm{a}}$ & $\mathrm{P}^{\mathrm{b}}$ \\
$\square \mathrm{N}=108 \square$ & $\square \mathrm{N}=17 \square$ & $\square \mathrm{N}=91 \square$ &
\end{tabular}

Clinical characteristics

\begin{tabular}{|c|c|c|c|c|}
\hline Age(years) & $56 \pm 12$ & $64 \pm 12$ & $54(44,64)$ & $0.010 *$ \\
\hline Gender(male/female) & $62(57.4 \%) / 46(42.6 \%)$ & $9(52.9 \%) / 8(47.1 \%)$ & $53(58.2 \%) / 38(41.8 \%)$ & 0.685 \\
\hline HD duration(months) & $60(29,122)$ & $93 \pm 76$ & $58(27,113)$ & 0.299 \\
\hline $\begin{array}{l}\text { Follow-up } \\
\text { time(months) }\end{array}$ & $52(39,52)$ & $37(16,41)$ & $52(52,52)$ & $\square 0.001 *$ \\
\hline mCCI & $3(2,4)$ & $4.43 \pm 2.21$ & $3(2,4)$ & 0.060 \\
\hline $\mathrm{SBP}(\mathrm{mm} \mathrm{Hg})$ & $152 \pm 22$ & $142 \pm 26$ & $154 \pm 20$ & $0.037 *$ \\
\hline DBP(mm Hg) & $77 \pm 15$ & $72 \pm 18$ & $79 \pm 14$ & 0.080 \\
\hline MAP(mm Hg) & $101 \pm 18$ & $95 \pm 19$ & $104 \pm 13$ & 0.097 \\
\hline $\mathrm{PP}(\mathrm{mm} \mathrm{Hg})$ & $74 \pm 21$ & $70 \pm 18$ & $75 \pm 21$ & 0.367 \\
\hline Hemoglobin(g/L) & $112.69 \pm 10.49$ & $109.72 \pm 9.63$ & $113.00(106.67,117.6)$ & 0.236 \\
\hline $\mathrm{WBC}\left(\mathrm{x} 10^{\wedge} 9 / \mathrm{L}\right)$ & $6.16(5.18,7.74)$ & $6.49 \pm 2.18$ & $6.12(5.22,7.58)$ & 0.565 \\
\hline $\mathrm{PLT}\left(\mathrm{x} 10^{\wedge} 9 / \mathrm{L}\right)$ & $164.38 \pm 53.48$ & $131.77 \pm 50.35$ & $169.62 \pm 52.36$ & $0.013^{*}$ \\
\hline Glucose(mmol/L) & $6.12(5.22,7.92)$ & $8.21 \pm 3.51$ & $6.03(5.20,7.41)$ & 0.176 \\
\hline Albumin(g/L) & $40.75(38.25,42.45)$ & $37.76 \pm 3.86$ & $40.68 \pm 3.52$ & $0.003^{*}$ \\
\hline $\mathrm{Hs}-\mathrm{CRP}(\mathrm{mg} / \mathrm{L})$ & $1.89(0.57,4.82)$ & $4.42(2.28,10.40)$ & $1.72(0.47,4.38)$ & $0.045^{*}$ \\
\hline $\mathrm{SF}(\mathrm{ug} / \mathrm{L})$ & $296.99 \pm 165.25$ & $299.37 \pm 140.31$ & $296.59 \pm 169.85$ & 0.956 \\
\hline $\mathrm{eGFR}(\mathrm{ml} / \mathrm{min} \times 1.73 \mathrm{~m} 2)$ & $15.26(12.61,18.31)$ & $17.81 \pm 6.92$ & $15.16(12.57,17.80)$ & 0.788 \\
\hline $\mathrm{spKt} / \mathrm{V}$ & $1.53 \pm 0.29$ & $1.43 \pm 0.35$ & $1.54 \pm 0.28$ & 0.168 \\
\hline Phosphate(mmol/L) & $1.77 \pm 0.52$ & $1.73 \pm 0.48$ & $1.66(1.40,2.14)$ & 0.745 \\
\hline Calcium(mmol/L) & $2.33 \pm 0.28$ & $2.26 \pm 0.23$ & $2.35 \pm 0.28$ & 0.258 \\
\hline $\mathrm{PTH}(\mathrm{pg} / \mathrm{ml})$ & $328.89(169.80,487.40)$ & $294.45 \pm 166.70$ & $348.46(172.24,525.92)$ & 0.216 \\
\hline \multicolumn{4}{|l|}{ Complement factors } & \\
\hline $\mathrm{C} 3 \mathrm{c}(\mathrm{g} / \mathrm{L})$ & $0.92 \pm 0.17$ & $0.98 \pm 0.21$ & $0.91 \pm 0.16$ & 0.154 \\
\hline $\mathrm{C} 1 \mathrm{q}(\mathrm{mg} / \mathrm{L})$ & $201.84 \pm 41.43$ & $209.34 \pm 39.79$ & $200.44 \pm 41.79$ & 0.419 \\
\hline $\mathrm{CFH}(\mathrm{ug} / \mathrm{mL})$ & $361.77 \pm 57.63$ & $388.64 \pm 75.32$ & $361.21 \pm 57.06$ & 0.169 \\
\hline $\mathrm{CFB}(\mathrm{mg} / \mathrm{L})$ & $346.15(299.93,388.20)$ & $355.5(288.55,430.70)$ & $346.10(302.40,387.20)$ & 0.358 \\
\hline $\mathrm{C} 4(\mathrm{~g} / \mathrm{L})$ & $0.31(0.25,0.38)$ & $0.33(0.28,0.49)$ & $0.31(0.24,0.38)$ & 0.205 \\
\hline MAC (ng/mL) & $482.26(307.59,783.75)$ & $401.80(325.65,981.94)$ & $484.32(294.83,758.05)$ & 0.440 \\
\hline
\end{tabular}




\begin{tabular}{|c|c|c|c|c|}
\hline $\mathrm{C} 5 \mathrm{a}(\mathrm{ng} / \mathrm{mL})$ & $31.03 \pm 10.80$ & $28.13 \pm 9.70$ & $31.57 \pm 10.97$ & 0.230 \\
\hline C3a(ng/mL) & $238.72(190.12,318.95)$ & $297.30 \pm 98.01$ & 229.03(182.10,294.49) & 0.339 \\
\hline $\operatorname{MBL}(\mathrm{ng} / \mathrm{mL})$ & $4346.38(1415.73,8979.95)$ & $4648.01 \pm 4040.82$ & $4807.28(1466.52,9043.82)$ & 0.471 \\
\hline \multicolumn{4}{|l|}{ Primary cause of ESRD } & 0.415 \\
\hline $\begin{array}{l}\text { Primary } \\
\text { glomerulopathy }\end{array}$ & $37(34.3 \%)$ & $5(29.4 \%)$ & $32(35.2 \%)$ & \\
\hline Diabetes & $14(13.0 \%)$ & $2(11.8 \%)$ & $12(13.2 \%)$ & \\
\hline Hypertension & $14(13.0 \%)$ & $4(23.5 \%)$ & $10(11.0 \%)$ & \\
\hline ADTKD & $10(9.3 \%)$ & 0 & $10(11.0 \%)$ & \\
\hline $\begin{array}{l}\text { Tubulointerstitial } \\
\text { nephropathy }\end{array}$ & $17(15.7 \%)$ & $2(11.8 \%)$ & $15(16.5 \%)$ & \\
\hline Other or unknown & $16(14.8 \%)$ & $4(23.5 \%)$ & $12(13.2 \%)$ & \\
\hline \multicolumn{5}{|l|}{ Comorbidity } \\
\hline CCDs & $39(36.1 \%)$ & $9(52.9 \%)$ & $30(33.0 \%)$ & 0.116 \\
\hline Hypertension & 77(71.3\%) & $8(47.1 \%)$ & $69(75.8 \%)$ & $0.034^{*}$ \\
\hline Diabetes & $12(11.1 \%)$ & $2(11.8 \%)$ & $10(11.0 \%)$ & 1.000 \\
\hline \multicolumn{5}{|c|}{$\begin{array}{l}\text { Data are shown as mean } \pm \text { SD or median (interquartile range) for continuous variables and proportions for categorical } \\
\text { variables. } \mathrm{P}<0.05 \text { are marked with *. }\end{array}$} \\
\hline \multicolumn{5}{|c|}{$\begin{array}{l}\text { aThe alive refers to patients who weren't dead until the end of their censoring time }(\mathrm{N}=91) \text {, including those undergoing } \\
\text { maintenance hemodialysis }(\mathrm{N}=75) \text { and receiving renal transplantation or transferring to other hospitals }(\mathrm{N}=16) \text { during the } \\
\text { follow-up. }\end{array}$} \\
\hline \multicolumn{5}{|c|}{$\begin{array}{l}\text { HD duration, hemodialysis duration; mCCI, modified Charlson comorbidity index; SBP, systolic blood pressure; DBP, } \\
\text { diastolic blood pressure; MAP, mean arterial blood pressure; PP, pulse pressure; WBC, white blood cell; PLT, blood platelet; } \\
\text { Hs-CRP, high-sensitivity C-reactive protein; SF, serum ferritin; eGFR, estimated glomerular filtration rate; PTH, parathyroid } \\
\text { hormone; CFH, complement factor H; CFB, complement factor B; MAC, membrane attack complex, complement C5b-9; } \\
\text { MBL, mannose-binding lectin. }\end{array}$} \\
\hline
\end{tabular}

During 52 months follow-up period, 17 patients died. 16 survived patients received renal transplantation or transferred to other dialysis centers, and the other 75 maintained HD in our center (Figure 1). The primary cause of death of the 17 patients was cardiovascular $(n=7,41.2 \%)$ and cerebrovascular $(n=2,11.8 \%)$ events (CCEs). Infection $(n=5,29.4 \%)$ took up the secondary place. Moreover, other six cases attacked by cardiovascular $(n=4)$ or cerebrovascular $(n=2)$ events, survived and maintained HD until the end of the study. In total, 23 patients achieved the composite endpoint (Figure 2).

\subsection{Clinical parameters and plasma complement factors associated with the prognosis by univariate Cox regression analysis}

To identify the correlation between clinical parameters and the prognosis of HD patients, we collected multiple possible indexes reported previously (8) to conduct univariate Cox regression for three endpoints, including death, CCEs and the composite endpoint (Table 2). Seven factors have been identified to be significantly associated with all-cause mortality, one with the incidence of CCEs and four with the composite endpoint. Remarkably, a high level of plasma C4 was significantly associated with all of the three endpoints ( $\mathrm{HR}, 5.039 ; 95 \% \mathrm{Cl}, 1.337-18.998 ; \mathrm{P}=0.017$ for allcause mortality, $\mathrm{HR}, 4.497 ; 95 \% \mathrm{Cl}, 1.117-18.104 ; \mathrm{P}=0.034$ for CCEs, $\mathrm{HR}, 3.927 ; 95 \% \mathrm{Cl}, 1.120-13.769 ; \mathrm{P}=0.033$ for the composite endpoint). Aging was associated both with an increased all-cause mortality $(\mathrm{HR}, 1.059 ; 95 \% \mathrm{Cl}, 1.012-1.108 ; \mathrm{P}=0.013)$ and incidence of composite endpoint (HR, $1.054 ; 95 \% \mathrm{Cl}, 1.015-1.094 ; \mathrm{P}=0.006)$, and $\mathrm{mCCl}$ score showed a similar trend $(\mathrm{HR}, 1.295 ; 95 \% \mathrm{Cl}, 1.034-1.622 ; \mathrm{P}=0.024$ for all-cause mortality, $\mathrm{HR}$, $1.245 ; 95 \% \mathrm{Cl}, 1.025-1.512 ; \mathrm{P}=0.027$ for the composite endpoint). An elevated blood platelet count was associated both with reduced risk of allcause mortality $(\mathrm{HR}, 0.987 ; 95 \% \mathrm{Cl}, 0.978-0.997 ; \mathrm{P}=0.009)$ and incidence of the composite endpoint $(\mathrm{HR}, 0.991 ; 95 \% \mathrm{Cl}, 0.983-0.999 ; \mathrm{P}=0.032)$. 


\subsection{Clinical parameters and plasma complement factors associated with the prognosis by multivariate Cox regression analysis}

For further exploration, we then performed multivariate Cox regression analyses to control confounding variables (Table 3). Model I was constructed to adjust for general clinical parameters, including age, gender, HD duration and mCCl. Based on model I, model II was additionally adjusted for other variables analyzed as $\mathrm{P}<0.1$ (including MAP, Albumin, Hs-CRP and spKt/V) in univariate Cox regression.

According to the models above, increased plasma C4 showed a significant association with the incidence of all three adverse endpoints, while blood platelet count showed the opposite effect. Specifically, a higher baseline plasma C4 associated with worse prognosis, including an increased risk of death (HR, 38.710; 95\% Cl, 5.23-286.68; $\mathrm{P}<0.001$ in model I and $\mathrm{HR}, 53.008 ; 95 \% \mathrm{Cl}, 3.62-779.65$; $\mathrm{P}=0.004$ in model II), incidence of CCEs (HR, 4.726; $95 \% \mathrm{Cl}, 1.19-18.78 ; \mathrm{P}=0.027$ in model $\mathrm{I})$ or achieving the composite endpoint $(\mathrm{HR}, 14.332 ; 95 \% \mathrm{Cl}, 2.93-70.21 ; \mathrm{P}=0.001$ in model I and $\mathrm{HR}, 14.747 ; 95 \% \mathrm{Cl}, 3.09-70.47 ; \mathrm{P}=0.001$ in model II). The patients with higher blood platelet count seemed to have reduced risk of death (HR, 0.980; 95\% Cl, 0.97-0.99; $\mathrm{P}=0.001$ in model I and $\mathrm{HR}, 0.969 ; 95 \% \mathrm{Cl}, 0.95-0.99 ; \mathrm{P}=0.001$ in model II) or achieving the composite endpoint (HR, 0.989; $95 \% \mathrm{Cl}, 0.98-0.99 ; \mathrm{P}=0.017$ in model I and $\mathrm{HR}, 0.990 ; 95 \% \mathrm{Cl}, 0.98-0.99 ; \mathrm{P}=0.033$ in model II).

Table 3

Multivariate Cox regression analyses for 3 endpoints.

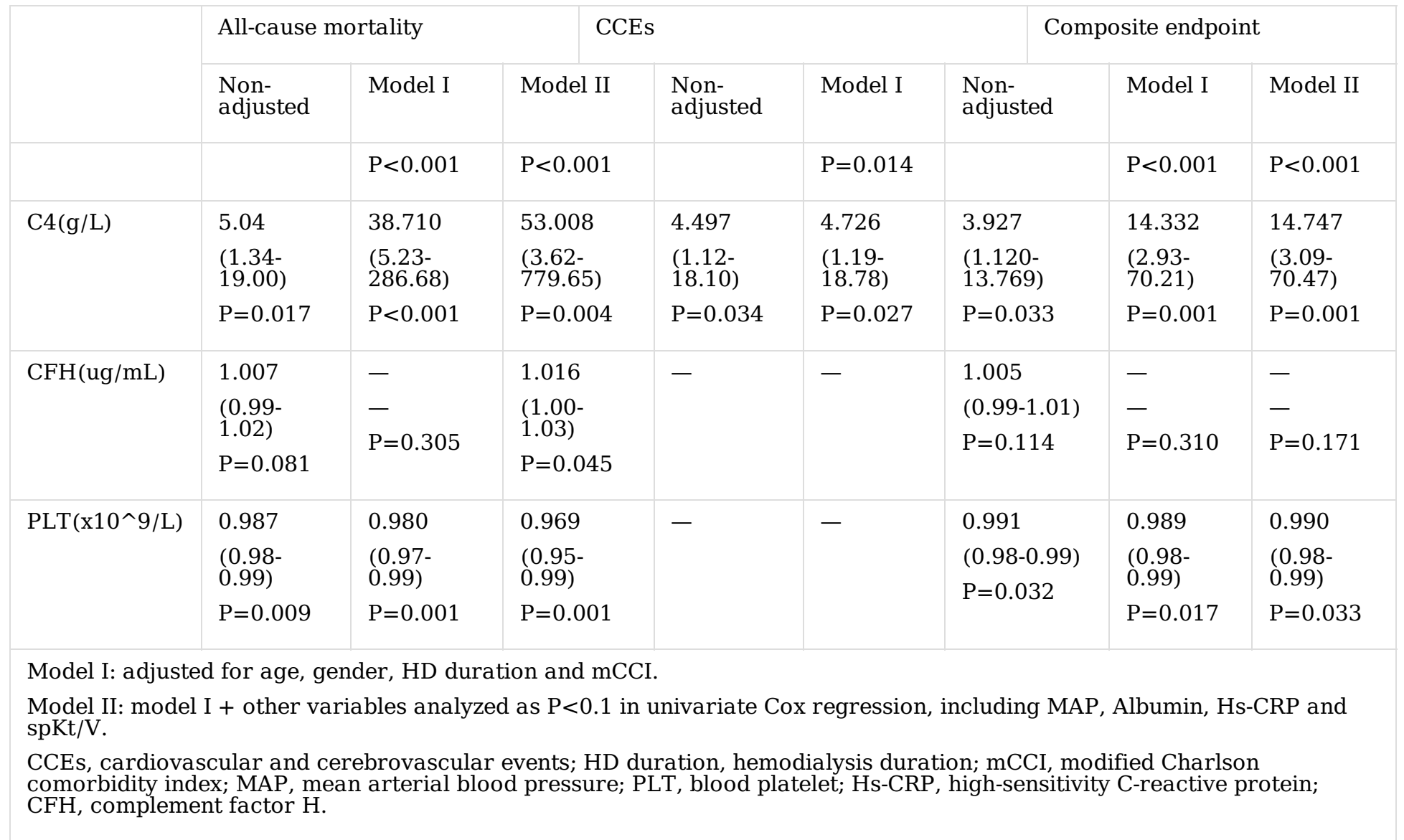

\subsection{Outcome-based cut-point optimization of complement factor 4 by X-tile analysis}

Since the baseline plasma C4 level may predict the prognosis of the cohort, X-tile analyses were performed (Figure 3). We tried to determine the optimal cut-off values for plasma C4 to identify patients with high risk for adverse outcomes. X-tile plots of the HD cohort displayed the optimal cut-off values. Histogram analyses of plasma C4 level showed a continuous distribution and were separated by the values in two colors. These divisions were applied to chart Kaplan-Meier plots and calculate the corresponding Log Rank (Mantel-Cox) chi-square and $\mathrm{P}$ values. In total, $\mathrm{X}$-tile analyses revealed that once plasma C4 was higher than $0.47\left(c^{2}=11.386, P=0.001\right)$ or $0.44\left(c^{2}=5.616, P=0.018\right) \mathrm{g} / \mathrm{L}$ respectively, the risk of death (Figure $3 \mathrm{a}$ ) or suffering either death or being attacked by CCEs (Figure $3 \mathrm{c}$ ) increased significantly. The optimal cut-off value for CCEs was $0.39 \mathrm{~g} / \mathrm{L}$ (Figure $3 b)$, but with no statistical significance $\left(c^{2}=3.615, P=0.057\right)$.

Page 6/13 


\subsection{Dose-response analysis of plasma C4 level with prognosis by restricted cubic spline model}

Restricted cubic spline model with 4 knots (Figure 4) was employed to simulate the relationship between plasma C4 level and the risk for three endpoints. T model was adjusted with age, gender, HD duration, mCCl, MAP, ALB, Hs-CRP and spKt/V. The relationships between plasma C4 level and HR for death ( $P$ for nonlinear trend $=0.8325$, for linear trend $=0.0087$, Figure $4 a$ ), the incidence of CCEs $(P$ for nonlinear trend $=0.3636$, for linear trend $=0.0358$, Figure $4 b$ ) and the composite endpoint ( $P$ for nonlinear trend $=0.2931$, for linear trend $=0.0191$, Figure $4 c$ ) were all observed as a linear tendency.

\subsection{Correlations between complement factors and the traditional risk factors for CCDs at baseline}

To further investigate possible mechanisms for the relationship between complement C4 and the prognosis, we assessed the correlations between complement factors and the traditional risk factors for CCDs at baseline. Apart from age, gender, blood pressure and diabetes mellitus or not, we detected the baseline blood lipids, containing triglyceride (TG), total cholesterol (TC), low-density lipoprotein cholesterol (LDL) and high-density lipoprotein cholesterol (HDL) among 78 of the $108 \mathrm{HD}$ patients. No significant difference in baseline characteristics between the 78 patients and the whole (Table S2).

Spearman's correlation analyses (Figure 5) indicated the strong positive correlations between C4, CFB, CFH and C3c, especially between CFB and C4 ( $r=0.82, P<0.001), C F H(r=0.86, P<0.001)$ and C3c $(r=0.82, P<0.001)$. Moreover, $C 4$ exhibited a prominent correlation with blood lipids, primarily with TG $(r=0.62, P<0.001)$ and HDL $(r=-0.38, P<0.001)$. Conversely, in our HD cohort, no significant correlations were revealed between $C 4$ and age $(r=-0.05, P=0.941), \operatorname{SBP}(r=-0.08, P=0.069), \operatorname{DBP}(r=-0.01, P=0.956)$ and diabetes mellitus $(r=0.11, P=0.668)$.

\section{Discussion}

The present study showed an association between the baseline plasma C4 level and the adverse outcomes, including all-cause mortality and CCEs, among patients receiving maintenance HD. Both in the unadjusted and adjusted models, plasma C4 level substantially showed a predictive value. Patients whose baseline plasma C4 $>0.47 \mathrm{~g} / \mathrm{L}$ or $0.44 \mathrm{~g} / \mathrm{L}$ in our cohort exhibited higher all-cause mortality or incidence of CCEs.

Meanwhile, the level of plasma C4 manifested a positive linear trend with HR for death, CCEs and either of them. In our cohort, baseline plasma C4 levels had correlations with blood lipids, which were widely acknowledged as risk factors for the development of cardiovascular diseases. These findings suggested that C4 may participate in the pathological processes in patients with maintenance HD and excess plasma C4 predicted worse prognosis for HD patients.

A body of evidence indicated that multiple complement components related to outcomes of HD patients, covering MBL (16-18), C3 (19), C1qadiponectin (2), MAC (19), CFH (20) and CR1 (21). A higher level of plasma C3 before an HD session, was reported to be associated with a higher probability of cardiovascular events (19). Baseline sC5b-9 levels was predicted to be correlated with cardiovascular events and mortality. A lower level of serum C1q-adiponectin/C1q ratios were also identified as a prognostic marker of cardiovascular diseases (2). Thus, a possible explanation would be that both an elevated complement activation and an intensified complement activity have been the risk factors for cardiovascular diseases. Additionally, Satomura et al. revealed that a lower MBL level could independently predict all-cause mortality in HD patients (16), which was also proposed to be linked with the morbidity of cardiovascular diseases in HD patients (17) and linked to accelerate arterial stiffness in HD patients (28).

Our previous cross-sectional study in the same cohort, found that the complement system was activated in patients on hemodialysis and a higher plasma C3a level prior a dialysis session was associated with severe abdominal aortic calcification (15). Thus, we included all measured plasma complement factors to identify the critical components associated with the outcomes. As a consequence, an elevated level of plasma C4 was proposed to be the risk factor that significantly increased all-cause mortality and incidence of CCEs, independent of other risk factors reported previously (8). Although plasma C4 level among hemodialysis patients $(0.312 \mathrm{~g} / \mathrm{L}(0.25 \mathrm{~g} / \mathrm{L}, 0.38 \mathrm{~g} / \mathrm{L}))$ wasn't prominently higher $(\mathrm{P}=0.10)$ than the normal $(0.285 \mathrm{~g} / \mathrm{L}(0.22 \mathrm{~g} / \mathrm{L}, 0.39 \mathrm{~g} / \mathrm{L}))(15)$, an increased level of plasma C4 could discriminate patients with adverse outcomes.

In the complement cascades, C4 contributes to the formation of C3 convertase in the classical and lectin pathway. Circulating C4 and C3 mainly derive from hepatocytes (29) and are also related to adipose tissue variables (30) and involved in the development of visceral adiposity (31). In healthy individuals, the polymorphism of $\mathrm{C} 4$ genes, including the variation of the gene copy number, the gene size and the C4 isotypes (C4A and C4B), largely determines the plasma levels and functions of C4 (32). An elevated level of plasma C4, as well as C3, are reported as strong inflammatory indicators of metabolic syndrome $(33,34)$, cardiovascular diseases (22), thrombotic diseases (35) and allergic diseases (36). During the pathological process, C4 and C4a may play pivotal roles in chronic inflammation and tissue injury, rather than defending against pathogens 
and cleaning immune complex and cells (37). The elevated systemic C4 and C3 levels were probably correlated with metabolic syndrome (33, 34, 37 ), which is proved to raise the risk of cardiovascular disease, diabetes and all-cause mortality among general population (38). Although our study confirmed the critical impact of plasma C4, plasma C3 level wasn't measured in the analyses. As we mentioned above, in those studies reported the correlation between $\mathrm{C} 3$ and prognosis, the plasma C4 levels were not measured. Further investigations are also needed to answer the relationship between $\mathrm{C} 3$ and $\mathrm{C} 4$, and their predictive value for prognosis in patients with maintenance HD.

Apart from the well-known conjunction in complement pathways, C4 may have distinct effects on metabolism and chronic inflammation (33). Studies of human populations have shown that C3 and C4 are associated with the incidence of myocardial infarction and stroke (22), as well as with their risk factors, such as obesity, hypertension, hyperlipemia and diabetes (28-31). Analogous associations were sighted in our HD cohort between plasma C4 and the incidence of CCEs and hyperlipemia. Cytokines stimulating the hepatic production of C4 may also induce hyperlipemia and undermine insulin sensitivity. C4 binding protein (C4BP) inhibits the classical and lectin pathway by binding to C4b and is reported as a protective factor for desired blood pressure, fasting blood glucose and $\beta$ cell function $(39,40)$. Furthermore, $\mathrm{C} 4 \mathrm{a}$, the product of $\mathrm{C} 4$ activation, may participate in cardiac remodeling and inflammation (41) by binding to protease-activated receptor I (PAR1) (42). Other components participating in the $\mathrm{C} 4$ activation, for example, platelets and endothelial cells (33), are receiving increasing attention due to their crosstalk in inflammation and vascular injury $(43,44)$. In our study, plasma C4 showed strong correlations with CFH, CFB, C1q and C3c. Thus, the impact of C4 on the prognosis in HD patients is likely to exert through the classic and alternative pathway.

Other baseline variables in our study, including demographic characteristics and laboratory measurements, were also included in the analyses as confounding factors. According to the univariate Cox regression, age, albumin, blood pressure, $\mathrm{mCCl}$ and comorbidity conditions were associated with prognosis, in consistent with previous studies $(8,25,45-50)$. Besides, a low level of blood platelet count was identified as a risk factor in our study. However, previous studies revealed that those with high platelet count ( $\left.>300 \times 10^{\wedge} 9 / \mathrm{L}\right)$ exhibited higher cardiovascular mortality (51). Given the fact above, therapies targeting or affecting platelet need to be individualized and refined among HD patients. The dialyzer is considered to exert remarkable impacts on the count, morphology and function of platelet $(52,53)$, worsening the already undesired platelet dysfunction (thrombosis and bleeding diathesis) in patients with ESRD (51). Considerable activation of platelet can occur during HD session, owing to the exposure of dialysis membrane (52). Whether the platelet activation by dialyzer contributes to the elevated all-cause mortality and incidence of CCEs in HD patients remains inconclusive.

Nevertheless, there are some limitations in our study. The case volume of the prospective analyses was relatively low, so limited endpoint events were observed. Patients enrolled in our study were used as training population to determine the hazard thresholds of plasma C4 level, thus a validation population is needed to further confirm the optimal value. C4 is cleaved by $\mathrm{C} 1 \mathrm{~s}$ (54) and mannan-binding lectin-associated serine protease 2(MASP2) (55) to release C4a and C4b to produce C3 convertase subsequently. Thus, weather the downstream fragments of C4 activation, such as $\mathrm{C} 4 \mathrm{a}$ and $\mathrm{C} 4 \mathrm{~d}$, have the correlations with the prognosis in HD patients is further to be excavated.

In conclusion, a high level of baseline plasma C4 was confirmed to be associated with all-cause mortality and the incidence of CCEs. Consequently, plasma C4 level is recommended as an innovative clinical predictor for HD patients, together with other risk-related variables, such as age, blood pressure, albumin, blood platelet count, etc. Further studies are required to thoroughly elucidate the significance and mechanisms of plasma C4 in HD patients.

\section{Abbreviations}

HD: Hemodialysis; CCDs: Cardiovascular and cerebrovascular diseases; C3c: Complement factor 3c; C1q: Complement factor 1q; CFH: Complement factor H; CFB: Complement factor B; C4: Complement factor 4; MAC: Membrane attack complex; C5a: complement factor 5a; C3a: Complement factor 3a; MBL: Mannose-binding lectin; CCEs: Cardiovascular and cerebrovascular events; ESRD: End-stage renal disease; CKD: Chronic kidney disease; CR1: Complement receptor 1; Hs-CRP: Hypersensitive C-reactive protein; mCCl: Modified Charlson comorbidity index; CABG: Coronary artery bypass grafting; PCl: Percutaneous coronary intervention; Cls: Confidence intervals; HR: hazard ratio; eGFR: Estimated glomerular filtration rate; SBP: systolic blood pressure; DBP: diastolic blood pressure; MAP: mean arterial blood pressure; PP: Pulse pressure; WBC: white blood cell; PLT: blood platelet; SF: serum ferritin; PTH: parathyroid hormone; TG: triglyceride; TC: total cholesterol; LDL: low-density lipoprotein cholesterol; HDL: High-density lipoprotein cholesterol; MetS: metabolic syndrome; C4BP: C4 binding protein; PAR1: protease-activated receptor l; MASP2: Mannan-binding lectin-associated serine protease 2.

\section{Declarations}

\section{Ethics approval and consent to participate}

This project was approved by the Ethics Committee of Peking University First Hospital (ethical approval number: 2015[1012]). All patients participating in this study were informed, signed informed consents and voluntarily participated. 


\section{Consent for publication}

Not applicable.

\section{Availability of data and materials}

The datasets generated and/or analyzed during the current study are not publicly available due to the fact that the patients consented their clinical statistics being used only for research but not sharing to the public repository, but are available from the corresponding author on reasonable request.

\section{Competing interests}

All the authors declared no competing interests.

\section{Funding}

This study was funded by the National Natural Science Foundation of China (81270820).

\section{Acknowledgments}

We are very grateful to Professor Xue-ying Li for assistance in medical statistics.

\section{Author's Contributions}

Z.Y.X. and Y.Q.C. prepared the manuscript, designed the study and organized the coordination. Y.Q.W. and K.J.G. collected the specimens and basic characteristics of all the patients. Y.Q.W. performed the experiments. Z.Y.X. conducted the patient follow-up and data analyses. All the authors read and approved the final manuscript.

No animal studies were carried out by the authors for this article.

All experiments were performed in accordance with relevant guidelines and regulations.

\section{References}

1. Agarwal AK, Haddad NJ, Vachharajani TJ, Asif A. Innovations in vascular access for hemodialysis. Kidney Int. 2019;95(5):1053-63.

2. Kishida K, Kishida N, Arima M, Nakatsuji H, Kobayashi H, Funahashi T, et al. Serum C1q- binding adiponectin in maintenance hemodialysis patients. BMC Nephrol. 2013;14:50.

3. Pierratos A. New approaches to hemodialysis. Annu Rev Med. 2004;55:179-89.

4. Saran R, Robinson B, Abbott KC, Bragg-Gresham J, Chen X, Gipson D, et al. US Renal Data System 2019 Annual Data Report: Epidemiology of Kidney Disease in the United States. Am J Kidney Dis. 2020;75(1 Suppl 1):A6-a7.

5. Go AS, Chertow GM, Fan D, McCulloch CE, Hsu CY. Chronic kidney disease and the risks of death, cardiovascular events, and hospitalization. N Engl J Med. 2004;351(13):1296-305.

6. Cozzolino M, Mangano M, Stucchi A, Ciceri P, Conte F, Galassi A. Cardiovascular disease in dialysis patients. Nephrol Dial Transplant. 2018;33(suppl_3):iii28-iii34.

7. Ahmadmehrabi S, Tang WHW. Hemodialysis-induced cardiovascular disease. Semin Dial. 2018;31(3):258-67.

8. Ma L, Zhao S. Risk factors for mortality in patients undergoing hemodialysis: A systematic review and meta-analysis. Int J Cardiol. 2017;238:151-8.

9. Ekdahl KN, Soveri I, Hilborn J, Fellstrom B, Nilsson B. Cardiovascular disease in haemodialysis: role of the intravascular innate immune system. Nat Rev Nephrol. 2017;13(5):285-96.

10. Craddock PR, Fehr J, Brigham KL, Kronenberg RS, Jacob HS. Complement and leukocyte-mediated pulmonary dysfunction in hemodialysis. N Engl J Med. 1977;296(14):769-74. 
11. Chenoweth DE, Cheung AK, Henderson LW. Anaphylatoxin formation during hemodialysis: effects of different dialyzer membranes. Kidney Int. 1983;24(6):764-9.

12. Szebeni J. Complement activation-related pseudoallergy: a stress reaction in blood triggered by nanomedicines and biologicals. Mol Immunol. 2014;61(2):163-73.

13. Hempel JC, Poppelaars F, da Costa MG, Franssen CFM, de Vlaam TPG, Daha MR, et al. Distinct in vitro Complement Activation by Various Intravenous Iron Preparations. American Journal of Nephrology. 2017;45(1):49-59.

14. Lhotta K, Wurzner R, Kronenberg F, Oppermann M, Konig P. Rapid activation of the complement system by cuprophane depends on complement component C4. Kidney Int. 1998;53(4):1044-51.

15. Wang Y, Miao Y, Gong K, Cheng X, Chen Y, Zhao MH. Plasma Complement Protein C3a Level Was Associated with Abdominal Aortic Calcification in Patients on Hemodialysis. J Cardiovasc TransI Res. 2019;12(5):496-505.

16. Satomura A, Endo M, Fujita T, Ohi H, Ohsawa I, Fuke Y, et al. Serum mannose-binding lectin levels in maintenance hemodialysis patients: impact on all-cause mortality. Nephron Clin Pract. 2006;102(3-4):c93-9.

17. Poppelaars F, Gaya da Costa M, Berger SP, Assa S, Meter-Arkema AH, Daha MR, et al. Strong predictive value of mannose-binding lectin levels for cardiovascular risk of hemodialysis patients. J Transl Med. 2016;14(1):236.

18. Poppelaars F, Damman J, de Vrij EL, Burgerhof JGM, Saye J, Daha MR, et al. New insight into the effects of heparinoids on complement inhibition by C1-inhibitor. Clinical and Experimental Immunology. 2016;184(3):378-88.

19. Lines SW, Richardson VR, Thomas B, Dunn EJ, Wright MJ, Carter AM. Complement and Cardiovascular Disease-The Missing Link in Haemodialysis Patients. Nephron. 2016;132(1):5-14.

20. Buraczynska M, Ksiazek P, Zukowski P, Benedyk-Lorens E, Orlowska-Kowalik G. Complement factor H gene polymorphism and risk of cardiovascular disease in end-stage renal disease patients. Clin Immunol. 2009;132(2):285-90.

21. Buraczynska M, Ksiazek P, Wacinski P, Zukowski P, Dragan M, Bednarek-Skublewska A. Complement receptor 1 gene polymorphism and cardiovascular disease in dialyzed end-stage renal disease patients. Hum Immunol. 2010;71(9):878-82.

22. Engstrom G, Hedblad B, Janzon L, Lindgarde F. Complement C3 and C4 in plasma and incidence of myocardial infarction and stroke: a population-based cohort study. Eur J Cardiovasc Prev Rehabil. 2007;14(3):392-7.

23. Keller TT, van Leuven SI, Meuwese MC, Wareham NJ, Luben R, Stroes ES, et al. Serum levels of mannose-binding lectin and the risk of future coronary artery disease in apparently healthy men and women. Arterioscler Thromb Vasc Biol. 2006;26(10):2345-50.

24. Saevarsdottir S, Oskarsson 00 , Aspelund T, Eiriksdottir G, Vikingsdottir T, Gudnason V, et al. Mannan binding lectin as an adjunct to risk assessment for myocardial infarction in individuals with enhanced risk. Journal of Experimental Medicine. 2005;201(1):117-25.

25. Rattanasompattikul M, Feroze U, Molnar MZ, Dukkipati R, Kovesdy CP, Nissenson AR, et al. Charlson comorbidity score is a strong predictor of mortality in hemodialysis patients. Int Urol Nephrol. 2012;44(6):1813-23.

26. Charlson ME, Pompei P, Ales KL, MacKenzie CR. A new method of classifying prognostic comorbidity in longitudinal studies: development and validation. J Chronic Dis. 1987;40(5):373-83.

27. Camp RL, Dolled-Filhart M, Rimm DL. X-tile: a new bio-informatics tool for biomarker assessment and outcome-based cut-point optimization. Clin Cancer Res. 2004;10(21):7252-9.

28. Hornum M, Bay JT, Clausen P, Melchior Hansen J, Mathiesen ER, Feldt-Rasmussen B, et al. High levels of mannose-binding lectin are associated with lower pulse wave velocity in uraemic patients. BMC Nephrol. 2014;15:162.

29. Zarkadis IK, Mastellos D, Lambris JD. Phylogenetic aspects of the complement system. Dev Comp Immunol. 2001;25(8-9):745-62.

30. Nilsson B, Hamad OA, Ahlstrom H, Kullberg J, Johansson L, Lindhagen L, et al. C3 and C4 are strongly related to adipose tissue variables and cardiovascular risk factors. Eur J Clin Invest. 2014;44(6):587-96.

31. Warnberg J, Marcos A. Low-grade inflammation and the metabolic syndrome in children and adolescents. Curr Opin Lipidol. 2008;19(1):11-5.

32. Castley AS, Martinez OP. Molecular analysis of complement component C4 gene copy number. Methods Mol Biol. 2012;882:159-71.

33. Xin Y, Hertle E, van der Kallen CJH, Schalkwijk CG, Stehouwer CDA, van Greevenbroek MMJ. Complement C3 and C4, but not their regulators or activated products, are associated with incident metabolic syndrome: the CODAM study. Endocrine. 2018;62(3):617-27.

34. Liu Z, Tang Q, Wen J, Tang Y, Huang D, Huang Y, et al. Elevated serum complement factors 3 and 4 are strong inflammatory markers of the metabolic syndrome development: a longitudinal cohort study. Sci Rep. 2016;6:18713.

35. Dahm AEA, Jacobsen EM, Wik HS, Jacobsen AF, Mollnes TE, Kanse SM, et al. Elevated Complement C3 and C4 Levels are Associated with Postnatal Pregnancy-Related Venous Thrombosis. Thromb Haemost. 2019;119(9):1481-8.

36. Mosca T, Menezes MC, Dionigi PC, Stirbulov R, Forte WC. C3 and C4 complement system components as biomarkers in the intermittent atopic asthma diagnosis. J Pediatr (Rio J). 2011;87(6):512-6.

37. Copenhaver M, Yu CY, Hoffman RP. Complement Components, C3 and C4, and the Metabolic Syndrome. Curr Diabetes Rev. 2019;15(1):44-8. 
38. Malik S, Wong ND, Franklin SS, Kamath TV, L'Italien GJ, Pio JR, et al. Impact of the metabolic syndrome on mortality from coronary heart disease, cardiovascular disease, and all causes in United States adults. Circulation. 2004;110(10):1245-50.

39. Liu X, Jiang C, Yang P. Association of single nucleotide polymorphisms in the 5 ' upstream region of the C4BPA gene with essential hypertension in a northeastern Han Chinese population. Mol Med Rep. 2017;16(2):1289-97.

40. Sjolander J, Byman E, Kulak K, Nilsson SC, Zhang E, Krus U, et al. C4b-binding Protein Protects beta-Cells from Islet Amyloid Polypeptideinduced Cytotoxicity. J Biol Chem. 2016;291(41):21644-55.

41. Antoniak S, Cardenas JC, Buczek LJ, Church FC, Mackman N, Pawlinski R. Protease-Activated Receptor 1 Contributes to Angiotensin II-Induced Cardiovascular Remodeling and Inflammation. Cardiology. 2017;136(4):258-68.

42. Wang HB, Ricklin D, Lambris JD. Complement-activation fragment C4a mediates effector functions by binding as untethered agonist to protease-activated receptors 1 and 4. Proceedings of the National Academy of Sciences of the United States of America. 2017;114(41):1094853.

43. Peerschke El, Yin W, Grigg SE, Ghebrehiwet B. Blood platelets activate the classical pathway of human complement. J Thromb Haemost. 2006;4(9):2035-42.

44. Nording H, Langer HF. Complement links platelets to innate immunity. Semin Immunol. 2018;37:43-52.

45. de Mutsert R, Grootendorst DC, Indemans F, Boeschoten EW, Krediet RT, Dekker FW. Association between serum albumin and mortality in dialysis patients is partly explained by inflammation, and not by malnutrition. J Ren Nutr. 2009;19(2):127-35.

46. Turner JM, Peixoto AJ. Blood pressure targets for hemodialysis patients. Kidney Int. 2017;92(4):816-23.

47. Lowrie EG, Huang WH, Lew NL. Death Risk Predictors among Peritoneal-Dialysis and Hemodialysis-Patients - a Preliminary Comparison. American Journal of Kidney Diseases. 1995;26(1):220-8.

48. Combe C, Chauveau P, Laville M, Fouque D, Azar R, Cano N, et al. Influence of nutritional factors and hemodialysis adequacy on the survival of 1,610 French patients. Am J Kidney Dis. 2001;37(1 Suppl 2):S81-8.

49. Ishii J, Takahashi H, Kitagawa F, Kuno A, Okuyama R, Kawai H, et al. Multimarker approach to risk stratification for long-term mortality in patients on chronic hemodialysis. Circ J. 2015;79(3):656-63.

50. Owen WF, Lew NL, Liu Y, Lowrie EG, Lazarus JM. The Urea Reduction Ratio and Serum-Albumin Concentration as Predictors of Mortality in Patients Undergoing Hemodialysis. New England Journal of Medicine. 1993;329(14):1001-6.

51. Molnar MZ, Streja E, Kovesdy CP, Budoff MJ, Nissenson AR, Krishnan M, et al. High platelet count as a link between renal cachexia and cardiovascular mortality in end-stage renal disease patients. American Journal of Clinical Nutrition. 2011;94(3):945-54.

52. Daugirdas JT, Bernardo AA. Hemodialysis effect on platelet count and function and hemodialysis-associated thrombocytopenia. Kidney Int. 2012;82(2):147-57.

53. Schoorl M, Schoorl M, Nubé MJ, Bartels PC. Coagulation activation, depletion of platelet granules and endothelial integrity in case of uraemia and haemodialysis treatment. BMC Nephrol. 2013;14:72.

54. Cooper NR. The Classical Complement Pathway: Activation and Regulation of the First Complement Component. In: Dixon FJ, editor. Advances in Immunology Volume 37. Advances in Immunology. 37: Academic Press; 1985. p. 151-216.

55. Rossi V, Cseh S, Bally I, Thielens NM, Jensenius JC, Arlaud GJ. Substrate specificities of recombinant mannan-binding lectin-associated serine proteases-1 and -2. J Biol Chem. 2001;276(44):40880-7.

\section{Table}

Table 2 is only available as a download in the Supplemental Files section.

\section{Figures}

\section{Figure 1}

Flow diagram of study design, patient recruitment and outcomes.

\section{Figure 2}

Causes of death and cardiovascular and cerebrovascular events (CCEs) in HD patients. Among the 108 HD patients, 17 deaths and 15 CCEs were recorded during the follow-up time. Cardiovascular and cerebrovascular events were the primary cause of death, accounting for $41.2 \%$ as seven 
and $11.8 \%$ as two respectively. Five patients died of infection, and three of the other causes including cancer, gastrointestinal hemorrhage and acute pancreatitis. In those 15 cases attacked by CCEs, six survived and were alive until the end of follow-up. In total, 23 patients achieved the composite endpoint.

\section{Figure 3}

X-tile analyses: determination of optimal cut-off values of plasma C4 for 3 endpoints. X-tile plots of 108 HD patients are shown in the first panels. The optimal cut-off values highlighted by the black circles in the first panels are detailed in the second panels, which are histograms revealing a continuous distribution based on plasma C4. Kaplan-Meier plots are displayed in third panels, with $\mathrm{P}$ values of the corresponding optimal cut-off value. The fourth panels demonstrate relative risk plots and the cut-off points are marked by yellow vertical bars. a The optimal cut-off value for all-cause death was $0.47\left(c^{2}=11.386, P=0.001\right)$. b The optimal cut-off value for CCEs was $0.39\left(c^{2}=3.615, P=0.057\right)$. c The optimal cut-off value for the composite endpoint was $0.44\left(c^{2}=5.616, P=0.018\right)$.

\section{Figure 4}

Association of plasma C4 level with the 3 endpoints in a restricted cubic spline model. Analyses were adjusted for age, gender, $\mathrm{HD}$ duration, mCCl, MAP, ALB, Hs-CRP and spKt/V. Multivariable adjusted hazard ratios (HRs; red line) with $95 \% \mathrm{Cl}$ (pink area) demonstrated the linear association of plasma C4 level with all-cause mortality (a), CCEs (b) and the composite endpoint (c).

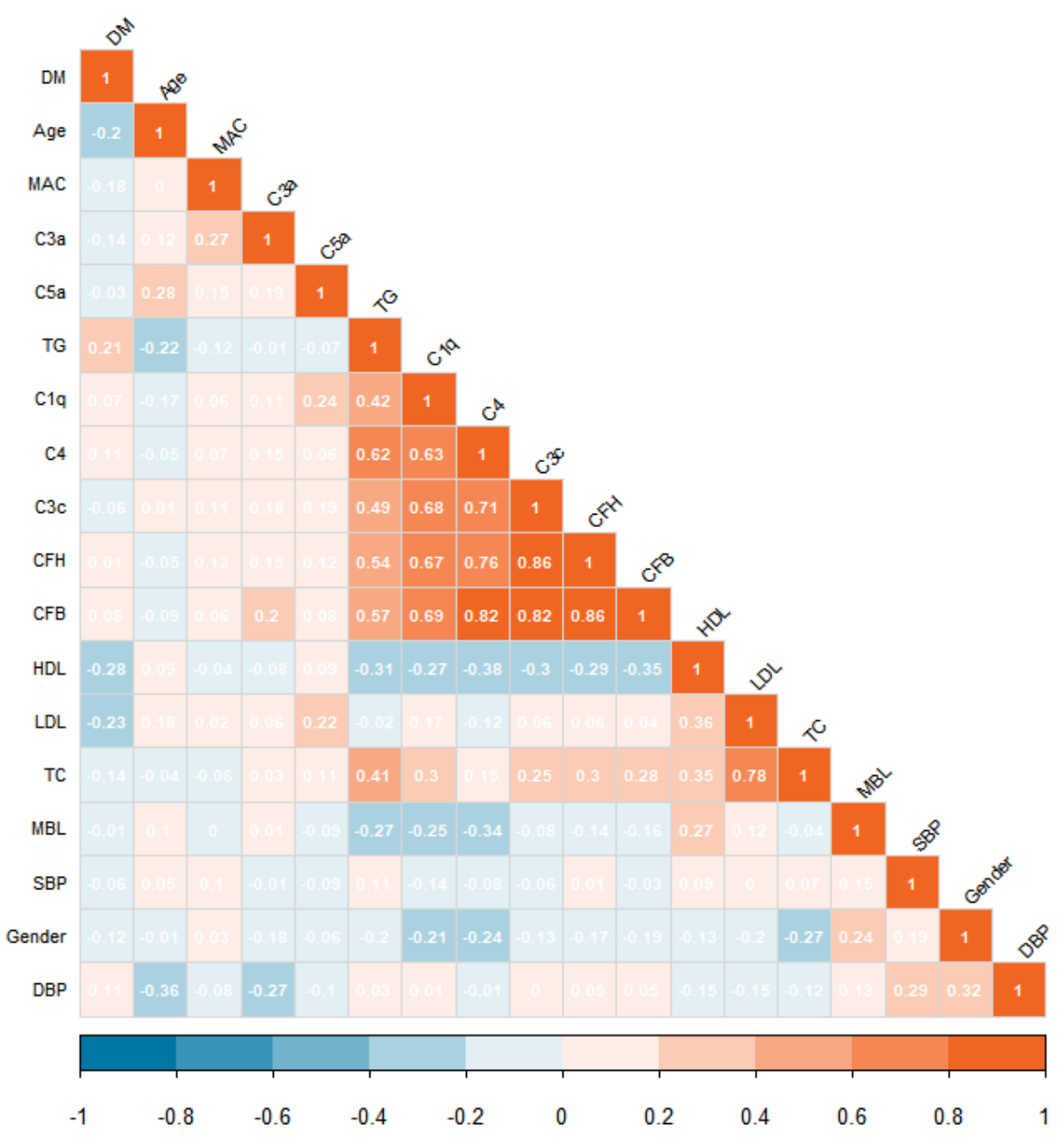

\section{Figure 5}

Correlation diagram of the complement factors and the traditional risk factors for CCEs. Spearman's correlation coefficients between the variables are shown as numbers with the corresponding grids colored according to the values. DM, diabetes mellitus; MAC, membrane attack complex, 
complement C5b-9; TG, triglyceride; CFH, complement factor H; CFB, complement factor B; HDL, high-density lipoprotein cholesterol; LDL, lowdensity lipoprotein cholesterol; TC, total cholesterol; MBL, mannose-binding lectin; SBP, systolic blood pressure; DBP, diastolic blood pressure.

\section{Supplementary Files}

This is a list of supplementary files associated with this preprint. Click to download.

- SupplementaryMaterial.docx

- Table2.docx 